This item was submitted to Loughborough's Research Repository by the author.

Items in Figshare are protected by copyright, with all rights reserved, unless otherwise indicated.

\title{
Compete or rest? Willingness to compete hurt among adolescent elite athletes
}

PLEASE CITE THE PUBLISHED VERSION

https://doi.org/10.1016/j.psychsport.2017.12.004

PUBLISHER

(c) Elsevier

VERSION

AM (Accepted Manuscript)

\section{PUBLISHER STATEMENT}

This work is made available according to the conditions of the Creative Commons Attribution-NonCommercialNoDerivatives 4.0 International (CC BY-NC-ND 4.0) licence. Full details of this licence are available at: https://creativecommons.org/licenses/by-nc-nd/4.0/

\section{LICENCE}

CC BY-NC-ND 4.0

\section{REPOSITORY RECORD}

Mayer, Jochen, Katrin E. Giel, Dominic Malcolm, Sven Schneider, Katharina Diehl, Stephan Zipfel, and Ansgar Thiel. 2019. "Compete or Rest? Willingness to Compete Hurt Among Adolescent Elite Athletes". figshare. https://hdl.handle.net/2134/27877. 
1 Title: Compete or rest? Willingness to compete hurt among adolescent elite athletes.

2 Running Head: Willingness to compete hurt among adolescent athletes

\section{Abstract}

Objective: Training and competing despite underlying health problems is a common social practice in sport. Adolescent elite athletes are particularly vulnerable to possible health consequences of this risky behavior due to their very sensitive developmental stage. Conceptualizing this phenomenon of playing hurt as sickness presenteeism, and taking the concept of absence/presence legitimacy into account, this paper analyzes the propensity of adolescent elite athletes to compete in the face of health problems. The central aim is to empirically identify characteristics of elite sport subcultures which affect athletes' willingness to compete hurt (WCH). Materials \& Methods: Based on a comprehensive sample of 1138 German elite adolescent athletes from all Olympic sports (14-18 years), the paper applies classification tree analysis to analyze the social and individual determinants of the WCH. Results: Determinants on three hierarchical levels were identified, including type of sport, perceptions of social pressure, coach’s leadership style and athletes' age. The group with the highest WCH were athletes from technical sports who have a coach with an autocratic leadership style. Second was athletes from ball games, and those in aesthetic and weight-dependent sports, aged between 17 and 18 years old. The lowest mean WCH-score, by some distance, occurred amongst the group of endurance and power sports athletes who experienced no direct social pressure to play hurt. Conclusions: The findings enhance our understanding of absence/presence legitimacy in highly competitive social contexts and contribute to the development of more effective target-group-specific health prevention programs for young athletes.

Keywords: Sickness presenteeism, playing hurt, culture of risk, elite sports, adolescent athletes 
Training and competing despite underlying health problems is a common practice in competitive sport. It often accompanies the use of painkillers, disregard of medical advice, or hiding pain from coaches and teammates (Howe, 2001; Malcolm, 2006; Pinheiro, Pimenta, Resende, \& Malcolm, 2014; Roderick, Waddington, \& Parker, 2000; Thiel, Mayer, \& Digel, 2010). This phenomenon of playing hurt (Roderick et al., 2000) is not only associated with short-term effects (e.g. exacerbated medical conditions), but also with long-term consequences such as the development of chronic overuse injuries, irreversible physical damage or recurring traumatic injuries (Kujala, Orava, Parkkari, Kaprio, \& Sarna, 2003; Waddington, 2000). Moreover, the consequences can negatively affect a successful sports career and hinder the ability to pursue an active lifestyle in later life. Adolescent elite athletes are particularly vulnerable to such short- and long-term consequences, as they have to cope with numerous physical, psychological and social changes during this very sensitive developmental stage. However, to the best of our knowledge, there are no studies addressing the problem of playing hurt which encompass a large scale representative sample of adolescent elite athletes across a range of sports.

Consequently, this paper analyzes the propensity of adolescent elite athletes to compete despite having a health problem. Particularly, the present study aims to identify specific groups of adolescent athletes who are willing to take the highest and lowest health risks in order to keep up their sports activity. As a consequence of identifying determinants of such high and low risk groups, it is possible to invoke strategies which will safeguard athletes' health and, in turn, enhance longer-term competitive performance. More specifically, such knowledge helps to better understand and improve return-to-play decision-making in elite sports. 


\section{Theoretical Framework}

Training and competing despite having a health problem can be conceptualized as sickness presenteeism in sport organizations (Mayer \& Thiel, 2016). Sickness presenteeism is generally defined as attending work while being ill (Aronsson, Gustafsson, \& Dallner, 2000) and is synonymous with keeping up social functioning despite having a medical condition or feeling ill. In this regard, decisions about presenteeism and absenteeism are generally conceptualized as resulting from the dynamic interplay of a current health event, various personal factors, and the organizational structures of the workplace (Johns, 2010). According to previous sociological research, the action fields of adolescent, elite and professional sports have to be considered as specific workplaces (Mayer \& Thiel, 2016; Roderick, 2006; Thiel et al., 2010). Like any regular worker, athletes are bound by contractual regulations and face various formal or informal role expectations and performance requirements. However, the elite sports workplace is also a special one, as excellent fitness and physical health are of extraordinary importance.

As outlined in the dynamic model of competing hurt in elite sport (Mayer \& Thiel, 2016), an athlete who experiences an acute, chronic or episodic health issue has to decide whether to show up for training, competition or other team events. In this regard, the characteristics of the work context influence presenteeism and absenteeism related decisions in two ways. First, situation specific expectations (e.g. the face-to-face order from a coach) can directly affect decision-making. Second, temporally outlasting expectations which result from the structure of the work context and other personal life circumstances can indirectly affect decision-making habits by shaping a persons'attitudes towards work. This includes an individual's absence/presence legitimacy, understood as the extent to which employees perceive presenteeism and absenteeism as acceptable work behavior (Addae, Johns, \& Boies, 2013; Harvey \& Nicholson, 1999). 
Based on this concept of absence/presence legitimacy, we argue that adolescent athletes develop a willingness to compete hurt (WCH). The $\mathrm{WCH}$ is defined as the extent to which an athlete perceives presenteeism and absenteeism as acceptable "work" behavior within their sports organization (Mayer \& Thiel, 2016). Thus, legitimizing a lay-off with very mild subjective complaints would imply a low WCH while a high willingness would be associated with the neglect of more severe medical conditions in order to compete. Consequently, an individual athlete's WCH represents an attitude and a highly relevant personal precondition to decision-making about pain, injury or illness related 'work' absence. As shown in a foregoing study of elite adult athletes (Mayer \& Thiel, 2016), there is generally a high willingness to compete despite subjective complaints and minor health problems. However, there is evidence that different athlete types exist, who are either rigidly rest averse or conditionally willing to rest.

In relation to competing despite health issues, both adolescent elite athletes and their coaches face a dilemma. On the one hand, the need to constantly push athletic bodies to the limit means that injuries are relatively routine. Thus, the acceptance of health risks is prevalent in competitive sports (Pike \& Maguire, 2003; Theberge, 2008) and evident amongst youth participants (Schubring \& Thiel, 2014). These findings suggest that athletes act within a culture of risk (Nixon, 1993) that is is closely entangled with the norms and values of what has been termed the sport ethic (Hughes \& Coakley, 1991); namely sacrifice for the game, seeking distinction, taking risks, and challenging limits. On the other hand, there is the need to take care of the athletes' health, as performance is often predicated on unimpaired physical function (Nixon, 1996). This, for instance, explains why elite adolescent athletes might exhibit a healthier lifestyle in terms of lower prevalences in smoking or ever consumption of alcohol relative to their non-athletic peers (Diehl, Thiel, Zipfel, Mayer, \& Schneider, 2014). Because elite adolescent athletes also need to succesfully cope with routine physical, psychological and social changes associated with youth transitions, this dilemma even 
becomes a trilemma (Diehl et al., 2014). Adolescent athletes seem to respond to this trilemma of risking ones' health vs. securing ones' health vs. coping with youth typical development tasks in various ways. There are findings of contrast groups with different degrees of a general physical and psychosocial risk acceptance (Schnell, Mayer, Diehl, Zipfel, \& Thiel, 2014), varying prevalences of eating disorders (Giel, Hermann-Werner, Mayer, Diehl, Schneider, Thiel, \& Zipfel, 2016) and increased rates of binge drinking (Diehl et al., 2014; Peretti-Watel, Guagliardo, Verger, Pruvost, Mignon, \& Obadia, 2003). However, we do not yet know how this elite youth sport trilemma is transformerd into the adolescent athletes' WCH and which factors predict higher and lower levels of such readiness for presenteeism in sports. This paper is the first to answer these questions.

\section{Predictors of the Willingness to Compete Hurt}

It is reasonable to suppose that the $\mathrm{WCH}$ is primarily mediated by processes of socialization into the context of competitive sports and progressively shaped through social expectations within elite sport organizations (organizational factors) and/or an athlete’s individual biography (individual factors).

Organizational factors: The essential raison d'être of elite sport organizations is the pursuit of high performance in competition. Irrespective of the sports discipline, this is not only a central goal for these organizations as entities but also for those members - coaches, managers, doctors, and athletes - who constitute what has been termed the "sportsnet" (Nixon, 1992). Moreover, presenteeism research illustrates that organization- and professionspecific absence/presence cultures play a major role in the collective avoidance of the sick role (Dew, Keefe, \& Small, 2005). Absence/presence cultures generally represent a "set of shared understandings about absence legitimacy and the established custom and practice of employee absence and control” (Johns \& Nicholson, 1982, p. 136). New workers acquire knowledge about legitimate causes for sick days, as well as knowledge about when they are 
socially expected to continue to work. As shown in relation to handball and track \& field, particular sports disciplines have specific presence/absence cultures that influence athletes' perceptions of absence legitimacy (Mayer \& Thiel, 2016). Within their teams, injured athletes can feel socially pressured to compete and risk being stigmatized as soft or as malingerers (Malcolm \& Sheard, 2002; Roderick, 2006; Roderick et al., 2000). Experiencing subtle or even direct social pressure to play hurt within their "sportsnet" can thus increase WCH. In this regard, the leadership style of the coach might also affect the way in which adolescent athletes perceive their health issues as legitmate reasons for absence. Finally, the extent of inclusion (Riedl, Borggrefe, \& Cachay, 2010) into the adolescent elite sports organizations also needs to be considered. Legitimitization of training abeyance due to health issues might be affected when athletes leave their families to join a sports boarding school or when they spend more time within the sports network due to higher training loads and competition days. As the social constraints to compete increase with performance level, internationally performing athletes might well show a higher WCH when compared with those at lower performance or squad-levels.

Individual factors: As athletes become progressively socialized into competitive sports cultures during adolescence, age must be considered as a potential predictive factor. Indeed, age has been shown to be closely related to presenteesim in non-athlete populations (Aronsson \& Gustafsson, 2005). Additionally there is evidence that females are less prone to presenteeism than males (Johns, 2010) and that perceptions of legitimate reasons for absences differ according to gender (Harvey \& Nicholson, 1999). However, findings from sport contexts indicate almost no gender differences on risk acceptance (Nixon, 1996; Schnell et al., 2014) and perceived absence/presence legitimacy (Mayer \& Thiel, 2016). In this regard, the effect of gender specific socialization processes during adolescence is not yet clear. 


\section{Purpose}

The main pupose of the article is to investigate the $\mathrm{WCH}$ in a comprehensive sample of elite adolescent athletes competing in nearly all Olympic sports. In particular, we explore the question as to whether there exist subsets of young elite athletes with notably different WCH values and thus identify which groups of athletes are willing to take the highest and lowest health risks in order to maintain their sports activity. Covering a wide range of potential determinants, we also use classification tree analysis to identify the influence and interaction of organizational and individual factors.

\section{Study Design}

\section{Materials and Methods}

The analysis is based upon data drawn from the German Young Olympic Athletes' Lifestyle and Health Management Study (GOAL Study), a multimethodical and interdisciplinary cooperative project funded by the Federal Institute of Sports Science (BISp), Germany, on behalf of the Federal Ministry of the Interior. The cross-sectional survey of all German elite adolescent athletes received ethical approval from the Medical Faculty

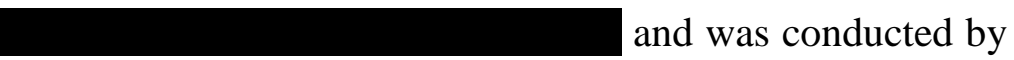

. As required by the ethics committee, written informed consent was received from each participant, allowing the inclusion of his or her data in the study.

Inclusion criteria for the athletes were: (a) engaging in one of the 54 Olympic sports (with respect to the 2010 Winter Olympics and 2012 Summer Olympics); (b) born between 1992 and 1995; and (c) competing at one of the highest four national squad levels (in Germany from A, B, C to D/C squad) or a corresponding team level. The federation 
responsible for Greco-Roman wrestling declined to participate and no athlete from either sailing or bobsledding met all the inclusion criteria, leaving a potential 1843 elite athletes from 51 sports included in the study. This population was contacted and asked to answer a self-administered questionnaire between February 2010 and January 2011. The only form of compensation for the participants was the opportunity to win one of 20 gift coupons (value: $50 €$ ) for a bookstore. The overall questionnaire covered several health-related topics (e.g. risky health behaviors, attitudes towards risk, subjective health) and included general sociodemographic variables as well as measures to asses the specific social context of sports (e.g. sport discipline, squad-level). The response rate was $61.75 \%$ ( $\mathrm{n}=1138 ; 56.1 \%$ male, age range 14-18), a particularly high response rate for a survey of this type (Baruch, 1999). A nonresponder analysis of age and gender did not show any significant differences between those who did and did not respond (for further details of the overall design and contents of the study, see

\section{Measures}

Based on theoretical reflections as well as previous quantitative and qualitative research, four items addressing typical health events which could lead to competition cessation were included in the comprehensive questionnaire. Item selection was driven by identification of ambiguous health events with uncertain medical consequences when competing. In addition, the health events should represent different dimensions of health and be recognized as common health issues from an athletes point of view.

The items were worded as "I"-statements and referred to both the physical and psychosocial dimensions of health (e.g. "I abstain from competing if... I have a fevery cold...have joint pain without moving, ...have to take painkillers, ... do not feel physically resilient). The athletes were asked to assess the extent of their agreement with the statements on a five-point Likert response format ranging from "strongly disagree” to "strongly agree”. 
These four items were then used to create a sum WCH score evaluating legitimate reasons for withdrawing from competition. Data were recoded by reversing scores so that higher values on the final sum scale (range 4-20) represent a higher WCH. As we conceptualized the WCH as a one dimensional, reflective construct to be measured through a multi-item reflective scale, we refer to Cronbach’s alpha as a measure for internal consistency. Construct validity was addressed by consensual validation including experts from sports science, sports medicine and sports coaching as no other directly related measures existed for testing construct validity. The theoretically derived independent variables used in this study are summarized in Table 1. In addition to individual characteristics such as age and gender, we focused on potential sport organizational context factors such as type of sport, squad level, weekly training load, yearly competition days, attendance of a sports boarding school, leadership style of the coach and the perception of direct or indirect pressures to compete hurt. Space restrictions within the comprehensive health questionnaire and the lack of previously validated short-scales for some of the sport organizational context factors led to the inclusion of self-developed single-item measures. In order to assess the perception of direct pressure to compete hurt, an item with the following wording was developed: "I am competing hurt because I feel pressured by the ones from my sporting environment”. The perceived indirect pressure to compete hurt was similarly assessed (wording: "I am competing hurt because I do not want to be called a wimp or weakling by my sporting peers”). For both measures, higher values on the five-point Likert response format represent a higher amount of perceived direct or indirect social pressure to compete hurt. Another single-item measure (nominal scale) was included to evaluate the leadership style of the coach. Considering the three major leadership styles (autocratic, democratic and laissez-faire) as established by Lewin, Lippit and White (1939), the exact wording of the variable is: "Which one of the following three statements fits best to the coach you spend most time with? In decision making situations... a)...my coach does mostly not allow any objection; b)...my coach is mostly willing to discuss the issue; 
c)...my coach mostly let's things pass. As no other directly related measures exist for testing construct validity for perceived social pressure and no other (longer) instruments on leadership styles could be included in the questionnaire, the problem of construct validity was addressed by consensual validation including experts from sports science and sports coaching.

\section{Data Analysis}

In order to identify and characterize groups with higher or lower WCH we used classification tree analysis. This method is considered a promising research tool for the identification of at-risk populations in public health research and outreach (Lemon, Roy, Clark, Friedmann, \& Rakowski, 2003) because it divides a sample population into different sub-populations based on the impact of predictors on the grouping variable. Compared to other multivariate methods, classification tree analyses have several advantages (see Camp \& Slattery, 2002; Chen, Shih, Lin, Chen, \& Lin, 2012). In addition to the ability to separate a population into subgroups whose members share common characteristics, simultaneous treatment of interactions among independent variables is possible. Moreover, the method is highly flexible, as it can handle a variety of variable types simultaneously (continuous, ordinal, or nominal) and does not require the stringent theoretical and distributional assumptions of more traditional methods (such as cluster analysis, discriminant analysis, and regression models).

The present classification tree analysis was performed via IBM SPSS 21 for Windows using the method of exhaustive CHAID. Exhaustive CHAID refers to a systematic algorithm to detect the strongest association between the target variable and independent variables. At each step, the independent variable with the strongest interaction with the dependent variable is chosen. The categories of each independent variable are merged if they are not significantly different with respect to the dependent variable. Each split in the decision tree is an optimal balance between sensitivity and specificity for predicting the outcome variable (Bühl, 2012; 
SPSS Inc., n.d.). The starting point of the analysis is the so-called "root node" at the top of a tree model, which contains the whole data set of the target variable.

The WCH score was employed as the target variable, with its outcomes ranging from four to 20. If a node splits to form part of a new level, it is referred to as a "parent node." Nodes splitting further from the parent node are termed "child nodes." Each node at the end of a branch is labeled a "terminal node." Terminal nodes represent the identified contrast groups. Nodes are represented by boxes including the mean value, standard deviation, absolute numbers, and percentage of the sample contained therein. Above each node, the name of the most significant predictor variable, the p-value, chi-squared value, and degrees of freedom are illustrated. The analysis incorporated different types of predictor variables, representing the aforementioned organizational and personal factors (see Table 1). For continuous dependent variables, data are automatically divided into approximate deciles and used as ordinal variables in the analysis (SPSS Inc., n.d.).

In order to "grow" the tree we chose the following parameters: a maximum tree depth of three, a minimum parent node size of 100 , a minimum child node size of 30 , and a significance threshold of 0.05 for splitting. Because the dependent variable is neither nominal nor ordinal, the misclassification risk is given by calculating the proportion of variance explained through the model using the risk estimators and the total variance of the root node (SPSS Inc., n.d.). Descriptive statistics, including means and standard deviations, were additionally performed for the four items pertaining to the $\mathrm{WCH}$ and for the predictor variables. 
Results

275

276

277

278

279

\section{Sample Distributions}

Mean age of the adolescent elite athletes was 16.33 years and $56 \%$ of the total sample ( $\mathrm{N}=1138)$ were male (see Table 1). According to the classification of Sundgot-Borgen and Torstveit (2004), most of them were engaged in ball games (36\%), in endurance (20\%), technical (13\%) and weight dependent sports (11\%). The weekly duration of sporting activity was 13.71 hours and the mean number of competition days during the previous season was 40.81. One out of five athletes (18\%) attended a sports related boarding school. The leadership style of the coach was described as democratic by $73 \%$ and as autocratic by $19 \%$ of athletes. Just over a third (36\%) of the athletes stated that they experienced medium to high pressure from their "sportsnet" to play hurt, while 39\% did not perceive any direct social pressure. More subtle forms of indirect social pressure like the fear of beeing called a weakling was perceived at a medium to high level by $16 \%$.

\section{Willingness to Compete Hurt}

Descriptive analysis of the WCH items showed that athletes were most likely to consider it legitimate to rest when they have a fevery cold (M: 3.97, SD: 1.25, Mdn: 4) (see Table 2). The most illegitimate reason for competition withdrawal was deemed to be a lack of feeling physically resilient (M: 2.77, SD: 1.24, Mdn: 3). Overall, the young elite athletes also tended to perceive joint pain as a reasonable cause to abstain from competing (M: 2.90, SD: 1.25, Mdn: 3). While no general tendency was observed in relation to the need to take painkillers (M: 3.05; SD: 1.43, Mdn: 3), 42.1\% of all athletes considered it illegitimate to rest while taking pain medication. Looking at the distibutions also reveals that $16.4 \%$ would not perceive it legitimate to rest with a fevery cold and almost half of the athletes showed a high willingness to compete despite health problems such as joint pain (43.8\%) or feeling not resilient (47.7\%). The mean overall WCH score is 11.29 (SD: 3.71) on a scale between 4 and 
20 (higher values represent a higher WCH). Reflecting the low number of included items and the narrow sample population, internal consistency is still acceptable (Cronbach's alpha=0.69). This score was used for the identification of high and low risk groups using classification tree analysis.

\section{Contrasting Groups for WCH}

On the basis of the most significant factors, which split the data set, the tree model depicted in Figure 1 was generated. The tree model demonstrates that the WCH is predicted by four interacting factors on three different levels. The variable with the strongest influence on the WCH was the type of sport (level 1). Directly perceived pressure and leadership style of the coach had the second strongest influence (level 2), but only for athletes in a particular group of sports. For example, the leadership style of the coach was only a significant factor in technical sports. Age was the next best predictor, indicating a significantly higher WCH in older athletes (level 3). However, the tree model indicates that age is only a significant factor when athletes are from aesthetic, ball games or weight dependent sports and when athletes experienced very low direct pressure to play hurt from their sportsnet. All the other variables, for example gender or squad level, had no significant influence on WCH. The proportion of variance explained by the classification tree model is $19.7 \%$, which indictates that there are additional influencing variables that were not included in our study.

Twelve different contrast groups with specific WCH scores and characteristics were identified according to the terminal nodes (Table 3). Comparison of the contrast group mean WCH-scores (cf. Table 3) indicates that five out of the 12 contrast groups have below average scores. In addition to the type of sports, four of the five below average contrast groups were characterized by either no or low direct social pressure to compete and by a young age. The two groups with the highest and the two groups with the lowest overall WCH were as follows. 
- The group with the highest WCH-score (14.73), consists of athletes from technical sports working under a coach with an autocratic leadership style. In total, 3.40\% of the study participants belong to this group (node 8).

- The group with the second highest WCH-score (12.98) consists of athletes from ball games and aesthetic and weight-categorized sports, but only those aged 17 and 18 and who experienced low direct social pressure to play hurt. Overall, $4 \%$ of the study participants belong to this group (node 17).

- The group with the second lowest WCH-score (9.39) consists of aesthetic, ball games and weight dependent sports athletes, who perceive no direct social pressure to play hurt and who are aged 14 and 15 (group size $4.6 \%$, node 13 ).

- The lowest mean WCH-score, by some distance (8.35), was detected amongst athletes in endurance and power sports, and who experienced no direct social pressure to compete hurt. In total, $12.2 \%$ of the study participants belong to this low risk group for playing hurt (node 10). 
modelling of multilevel interactions and simultaneous inclusion of more independent variables is a major advantage (Camp \& Slattery, 2002; Chen et al., 2012).

The descriptive analysis shows that adolescent athletes clearly differentiate between the legitimacy to rest according to particular kinds of underlying health problems. This finding is in line with observations in adult elite sports (Mayer \& Thiel, 2016) and with research addressing the legitimacy of various minor health conditions in normal work contexts (Harvey \& Nicholson, 1999). Two further findings are of considerable practical importance. Firstly, in view of the health risks of competing while using e.g. common nonsteroidal anti-inflammatory drugs (Van Wijck, Lenaerts, Van Bijnen, Boonen, Van Loon, Dejong, \& Buurman, 2012), it is alarming that $42.1 \%$ of athletes considered it illegitimate to rest while receiving medication. Secondly, in light of the short and long-term health risks involved in practicing high-intensity sports while having acute infectious diseases (Scharhag \& Meyer, 2014), it is of considerable concern that $16.4 \%$ are averse to resting when suffering from a fevery cold. Conversely, the descriptive results also show that more than half of the young athletes seem to have internalized a more cautious approach to playing hurt, and that they are far more willing than older elite athletes to withdraw from competition when feeling unwell (Mayer \& Thiel, 2016).

Although the study population is a very specific one, classification tree analysis revealed contrast groups with a varying propensity to take health risks in favor of competing. The group to which an athlete belonged was determined by several interacting factors on three different levels, including: type of sports; perception of direct social pressure to play hurt; leadership style of the coach; and athletes’ age. Generally, these findings correspond with our theoretical assumptions about the influence of distinct presence cultures and the degree of socialization into the elite sports system. However, it was further revealed that these factors only play a role in certain instances. Overall, the type of sports predefines the range of the 
WCH-score, while the other factors contribute to its specific location within this range. Athletes from technical sports, for example, have a higher acceptance of possible health risks compared to their peers from endurance, power or antigravitation sports. Even athletes from technical sports, whose WCH is slightly lower when having a non-autocratic coach, express higher values than the athlete groups from endurance, power or antigravitation sports.

The centrality of the sport discipline can be explained by differences in "adjustment latitude” (Johansson, Hultin, Moller, Hallqvist, \& Kjellberg, 2012). In endurance sports for example, having a cold or feeling unwell reduces work ability and severly inhibits high performance. In power sports, due to the often maximal strains to the athlete's body, it is also impossible to realize top performance whilst in pain or functionally impaired. In technical sports or ball games, in contrast, it is more likely that an athlete might still deliver the requested performance or contribute to the overall team performance while experiencing disease. Thus, our study supports the argument that the extent of taking health risks in sports is shaped by sport-specific performance norms and constraints which differently mediate what has broadly been defined as the 'culture of risk' in sports (Giel et al., 2016; Liston, McDowell, Malcolm, Scott, \& Waddington, 2016; Mayer \& Thiel, 2016; Schnell et al., 2014). However, our results emphasize that in addition to the sport-specific culture, a climate of pressure within the athletes' particular sportsnet further increases the extent of perceived absence legitimacy. Particularly in endurance and power sports we can see a higher WCH amongst athletes experiencing greater social pressure. This is also true for ball games, aesthetic and weight dependent sports, where age is an additional mediating factor. The younger the athletes within these sport disciplines, the less pressure to play they perceive, the easier is it for them to legitimize a break from competition. The findings about the general influence of social pressure is in line with Nixon's (1992) network-theoretical assumptions and observations within professional soccer and rugby clubs (Howe, 2001; Roderick, 2006). 
Given that older athletes who exhibit greater $\mathrm{WCH}$ are less eager to rest only in particular sport-discipline-social-pressure-constellations, we assume that in these cases socialization processes are particularly important; such as a stronger orientation to the fundamental values of elite sports (the sports ethic) or decreased influence of family and other non-sports related social environments (Riedl et al., 2010). As age does not prove to be a relevant factor in older athlete populations (Mayer \& Thiel, 2016), we suppose that such socialization processes into the elite sports cultures of risk are mostly completed by late adolescence.

Factors in the classification tree analysis that have no significant influence on the extent of the WCH are also of interest. In contrast to general presenteeism research (Johns, 2010), we found no significant influence of gender. Moreover, this result is in line with other quantitative findings addressing risk attitudes in competitive athletes (Nixon, 1996; Schnell et al., 2014). Thus, it can be hypothesized, a gender specific development of absence legitimacy is neutralized because highly specialized groups of elite athletes adopt the same fundamental values and structural principles within sport organizations, regardless of gender.

This study has several limitations. First, the study has the typical limitations of crosssectional survey studies that rely on self-reported variables. Second, it is not yet clear how the extent of WCH relates to an increased risk for developing serious long-term health problems. Moreover, as being overly cautious can also negatively affect sports careers, it is not clear to what degree a certain willingness for presenteeism is functional, for example for keeping up squad memberships or securing one's position within a team. Third, the relatively low level of internal consistency is a limitation as well, which should be addressed in further development of the WCH-measure. Fourth, the self-developed single-item measures for leadership style of the coach, direct and indirect perceived social pressure to compete hurt were not previously validated and psychometrically tested. These restrictions need to be cautiously considered when interpreting the results and drawing practical conclusions. However, the results also 
422

indicate that future endeavors should focus on developing validated and psychometrically tested (short) scales for aspects of social interaction such as perceived social pressure or leadership styles. Fifth, statistical analysis indicates that some potential influencing variables have yet to be identified. Sixth, our study only addressed the athletes' perspective. The extent to which coaches' expectations about playing hurt, and their perceptions of pressurizing athletes differ from their athletes', is yet to be addressed.

Future research should focus on longitudinal studies analyzing the relationship between long-term health developments and changing WCH across the sports career. This includes finding out at what point, and in which specific sports careers, it is beneficial/harmful to take particular risks. Such longitudinal studies should also include adolescent athletes from different nations, cultures and lower performance levels. It is also necessary that the present study is replicated with other samples of elite athletes in order to confirm the predictive capacity of the model. For a better explanation of the variance in WCH, other psychosocial measures should be included in future studies, such as exercise addiction, self-conceptions of health, health locus of control, self-efficacy, social integration or social status. A more holistic analysis would also include the coaches' perspective, and in particular their influence on the organizational norms of playing hurt and on the development of individual athletes' representations of health and healthy lifestyles.

\section{Conclusions}

Analyzing sickness presenteeism among adolescent elite athletes contributes to our understanding of how health problems are managed within the highly competitive sports context in general and during this sensitive developmental stage in particular. The identification and characterization of high and low risk groups for playing hurt is of practical 
447

use for return-to-play decision-making (Shrier, Matheson, Boudier-Reveret, \& Steele, 2015). Coaches and medical staff should reflect which athletes are more willing to play hurt than others, and consider this in all kinds of fitness and return-to-play decisions. Predominantly, those working within technical sports need to be aware of their ethical responsibility both in general and for adolescent athletes. Doctors and coaches who work within ball, aesthetic and weight-categorized sports need to be particularly careful when addressing issues about how to deal with minor health problems, as these athletes have a heightened sensitivity to the social expectations to play hurt. This is also true for endurance and power sports, where a social climate of pressure very likely results in an increased willingness to take pronounced health risks. In conclusion, excessive social pressure within the sports network needs to be targeted by establishing health-oriented decision-making regulations and athlete-focused communication strategies.

\section{References}

Addae, H. M., Johns, G., \& Boies, K. (2013). The legitimacy of absenteeism from work: A nine nation exploratory study. Cross Cultural Management: An International Journal, 20(3), 402-428. doi: 10.1108/Ccm.05.2012.0040

Aronsson, G., \& Gustafsson, K. (2005). Attendance presenteeism: Prevalence, attendancepressure factors, and an outline of a model for research. Journal of Occupational and Environmental Medicine, 47(9), 958-966. doi: 10.1097/01.jom.0000177219.75677.17

Aronsson, G., Gustafsson, K., \& Dallner, M. (2000). Sick but yet at work. An empirical study of sickness presenteeism. Journal of Epidemiology and Community Health, 54(7), 502-509. doi: 10.1136/jech.54.7.502 
Baruch, Y. (1999). Response rate in academic studies - A comparative analysis. Human Relations, 52(4), 421-438. doi: 10.1023/A:1016905407491

Bühl, A. (2012). SPSS 20: Einführung in die moderne Datenanalyse (SPSS 20: Introduction to modern data analysis) (13. ed.). München, Germany: Pearson.

Camp, N., \& Slattery, M. (2002). Classification tree analysis: A statistical tool to investigate risk factor interactions with an example for colon cancer (United States). Cancer Causes Control, 13(9), 813-823. doi: 10.1023/A:1020611416907

Chen, J., Shih, C., Lin, P., Chen, J., \& Lin, K. (2012). Collaborative evaluation and management of students' health-related physical fitness: Applications of cluster analysis and the classification tree. International Journal of Public Health, 24(2), 153159. doi: 10.1515/ijamh.2012.023

Dew, K., Keefe, V., \& Small, K. (2005). 'Choosing' to work when sick: Workplace presenteeism. Social Science \& Medicine, 60(10), 2273-2282. doi: 10.1016/j.socscimed.2004.10.022

Diehl, K., Thiel, A., Zipfel, S., Mayer, J., \& Schneider, S. (2014). Substance use among elite adolescent athletes: Findings from the GOAL Study. Scandinavian Journal of Medicine \& Science in Sports, 24(1), 250-258. doi: 10.1111/j.16000838.2012.01472.x

Giel, K. E., Hermann-Werner, A., Mayer, J., Diehl, K., Schneider, S., Thiel, A., \& Zipfel, S. (2016). Eating disorder pathology in elite adolescent athletes. International Journal of Eating Disorders, 49(6), 553-562. doi: 10.1002/eat.22511

Harvey, J., \& Nicholson, N. (1999). Minor illness as a legitimate reason for absence. Journal of Organizational Behavior, 20(6), 979-993. doi: 10.1002/(Sici)10991379(199911)20:6<979::Aid-Job914>3.0.Co;2-0 
Howe, P. D. (2001). An ethnography of pain and injury in professional Rugby Union. International Review for the Sociology of Sport, 36(3), 289-303. doi: $10.1177 / 101269001036003003$

Hughes, R., \& Coakley, J. (1991). Positive deviance among athletes - The implications of overconformity to the sport ethic. Sociology of Sport Journal, 8(4), 307-325. doi: dx.doi.org/10.1123/ssj.8.4.307

Johansson, G., Hultin, H., Moller, J., Hallqvist, J., \& Kjellberg, K. (2012). The impact of adjustment latitude on self-assessed work ability in regard to gender and occupational type. Scandinavian Journal of Occupational Therapy, 19(4), 350-359. doi: 10.3109/11038128.2011.603354

Johns, G. (2010). Presenteeism in the workplace: A review and research agenda. Journal of Organizational Behavior, 31(4), 519-542. doi: 10.1002/job.630

Johns, G., \& Nicholson, N. (1982). The meaning of absence: New strategies for theory and research. Research in Organizational Behavior, 4, 127-172.

Kujala, U. M., Orava, S., Parkkari, J., Kaprio, J., \& Sarna, S. (2003). Sports career-related musculoskeletal injuries: Long-term health effects on former athletes. Sports Medicine, 33(12), 869-875.

Lemon, S. C., Roy, J., Clark, M. A., Friedmann, P. D., \& Rakowski, W. (2003). Classification and regression tree analysis in public health: methodological review and comparison with logistic regression. The society of behavioral medicine, 26(3), 172-181. doi: 10.1207/S15324796ABM2603_02

Lewin, K., Lippit, R. \& White, R. K. (1939). Patterns of aggressive behavior in experimentally created social climates. Journal of Social Psychology, 10, 271-301.

Liston, K., McDowell, M., Malcolm, D., Scott, A., \& Waddington, I. (2016). On Being “Head Strong”: The Pain Zone and Concussion in Non-Elite Rugby Union. International Review for the Sociology of Sport. doi: 10.1177/1012690216679966 
Malcolm, D. (2006). Unprofessional practice? The status and power of sport physicians. Sociology of Sport Journal, 23(4), 376-395. doi: 10.1123/ssj.23.4.376

Malcolm, D., \& Sheard, K. (2002). "Pain in the assets": The effects of commercialization and professionalization on the management of injury in English Rugby Union. Sociology of Sport Journal, 19(2), 149-169. doi: 10.1123/ssj.19.2.149

Mayer, J., \& Thiel, A. (2016). Presenteeism in the elite sports workplace: The willingness to compete hurt among German elite handball and track and field athletes. International Review for the Sociology of Sport, 1-20. doi: 10.1177/1012690216640525

Nixon, H. L. (1992). A social network analysis of influences on athletes to play with pain and injury. Journal of Sport \& Social Issues, 16(2), 127-135. doi: $10.1177 / 019372359201600208$

Nixon, H. L. (1993). Accepting the risks of pain and injury in sport: Mediated cultural influences on playing hurt. Sociology of Sport Journal, 10(2), 183-196. doi: 10.1123/ssj.10.2.183

Nixon, H. L. (1996). Explaing pain and injury attitudes and experiences in sports in terms of gender, race, and sports status factors. Journal of Sport \& Social Issues, 20(1), 33-44. doi: $10.1177 / 019372396020001004$

Peretti-Watel, P., Guagliardo, V., Verger, P., Pruvost, J., Mignon, P., \& Obadia, Y. (2003). Sporting activity and drug use: Alcohol, cigarette and cannabis use among elite student athletes. Addiction, 98(9), 1249-1256.

Pike, E. C. J., \& Maguire, J. A. (2003). Injury in women's sport: Classifying key elements of 'risk encounters'. Sociology of Sport Journal, 20(3), 232-251. doi: $10.1123 /$ ssj.20.3.232

Pinheiro, M. C., Pimenta, N., Resende, R., \& Malcolm, D. (2014). Gymnastics and child abuse: An analysis of former international Portuguese female artistic gymnasts. Sport, Education and Society, 19(4), 435-450. doi: 10.1080/13573322.2012.679730 
547 Riedl, L., Borggrefe, C., \& Cachay, K. (2010). Elite sports versus university studies? Organizational changes and networking as structural solutions to the inclusion problem facing elite student athletes in Germany. In U. Wagner, R. K. Storm, \& J. Hoberman (Eds.), Observing sport. Modern system theoretical approaches (pp. 163196). Schorndorf, Germany: Hofmann.

Roderick, M. (2006). Adding insult to injury: Workplace injury in English professional football. Sociology of Health \& Illness, 28(1), 76-97. doi: 10.1111/j.14679566.2005.00483.x

Roderick, M., Waddington, I., \& Parker, G. (2000). "Playing hurt": Managing injuries in English professional football. International Review for the Sociology of Sport, 35(2), 165-180.

Scharhag, J., \& Meyer, T. (2014). Return to play after acute infectious disease in football players. Journal of Sports Sciences, 32(13), 1237-1242. doi: $10.1080 / 02640414.2014 .898861$

Schnell, A., Mayer, J., Diehl, K., Zipfel, S., \& Thiel, A. (2014). Giving everything for athletic success! - Sports-specific risk acceptance of elite adolescent athletes. Psychology of Sport and Exercise, 15(2), 165-172. doi: 10.1016/j.psychsport.2013.10.012

Schubring, A., \& Thiel, A. (2014). Coping with growth in adolescent elite sport. Sociology of Sport Journal, 31(3), 304-326. doi: 10.1123/ssj.2013-0071

Shrier, I., Matheson, G. O., Boudier-Reveret, M., \& Steele, R. J. (2015). Validating the threestep return-to-play decision model. Scandinavian Journal of Medicine \& Science in Sports, 25(2), e231-239. doi: 10.1111/sms.12306

SPSS Inc. (n.d.). PASW Desicion Trees 18. (pp. 106). Retrieved from http://www.sussex.ac.uk/its/pdfs/SPSS18_Decision_Trees.pdf

Sundgot-Borgen, J., \& Torstveit, M. K. (2004). Prevalence of eating disorders in elite athletes is higher than in the general population. Clin J Sport Med, 14(1), 25-32. 
573 Theberge, N. (2008). "Just a normal bad part of what I do": Elite athletes' accounts of the relationship between health and sport. Sociology of Sport Journal, 25(2), 206-222. doi: $10.1123 / \mathrm{ssj} .25 .2 .206$

Thiel, A., Diehl, K., Giel, K. E., Schnell, A., Schubring, A., Mayer, J., . . . Schneider, S. (2011). The German Young Olympic Athletes' Lifestyle and Health Management Study (GOAL Study): design of a mixed-method study. BMC Public Health, 11(1), 410. doi: 10.1186/1471-2458-11-410

Thiel, A., Mayer, J., \& Digel, H. (2010). Gesundheit im Spitzensport. Ein sozialwissenschaftliche Analyse (Health in elite sports. An analysis from a social sciences perspective). Schorndorf, Germany: Hofmann.

Van Wijck, K., Lenaerts, K., Van Bijnen, A. A., Boonen, B., Van Loon, L. J. C., Dejong, C. H. C., \& Buurman, W. A. (2012). Aggravation of exercise-induced intestinal injury by Ibuprofen in athletes. Medicine and Science in Sports and Exercise, 44(12), 22572262. doi: 10.1249/MSS.0b013e318265dd3d

Waddington, I. (2000). Sport, health and drugs. A critical sociological perspective. New York, NY: Taylor \& Francis. 
591 Table 1

592 Sample distribution by independent variables

\begin{tabular}{|c|c|c|c|c|}
\hline $\begin{array}{l}\text { Individual } \\
\text { characterisitcs }\end{array}$ & Subcategory & Absolute (N) & $\%$ & M (SD) \\
\hline \multirow{3}{*}{ Age } & & 1138 & & $\begin{array}{l}16.33 \\
(1.10)\end{array}$ \\
\hline & 14yrs/15yrs/16yrs & 67/201/319 & $6 / 18 / 28$ & - \\
\hline & 17yrs/18yrs & $393 / 158$ & $35 / 14$ & - \\
\hline \multirow{2}{*}{ Gender } & Females & 500 & 56 & - \\
\hline & Males & 638 & 44 & - \\
\hline \multicolumn{5}{|c|}{ Sport organizational context } \\
\hline \multirow{3}{*}{ Type of sport } & $\begin{array}{l}\text { Technical/Aesthetic/A } \\
\text { ntigravitation }\end{array}$ & $143 / 46 / 41$ & $13 / 4 / 3$ & - \\
\hline & $\begin{array}{l}\text { Endurance/Endurance } \\
\text {-high power }\end{array}$ & $222 / 79$ & $20 / 7$ & - \\
\hline & $\begin{array}{l}\text { Weight } \\
\text { dependent/Ball } \\
\text { games/Power }\end{array}$ & $125 / 407 / 71$ & $11 / 36 / 6$ & - \\
\hline \multirow{2}{*}{ Squad level } & $\begin{array}{l}\text { A-Squad (highest)/B- } \\
\text { Squad }\end{array}$ & $45 / 36$ & $4 / 3$ & \\
\hline & $\begin{array}{l}\text { C-Squad/DC-Squad } \\
\text { (lowest) }\end{array}$ & $492 / 490$ & $43 / 43$ & \\
\hline $\begin{array}{l}\text { Weekly training load } \\
\text { (hours) }\end{array}$ & & 1109 & - & $\begin{array}{l}13.71 \\
(5.37)\end{array}$ \\
\hline $\begin{array}{l}\text { Competition days } \\
\text { during last season }\end{array}$ & & 957 & - & $\begin{array}{l}40.81 \\
(30.76)\end{array}$ \\
\hline \multirow{2}{*}{$\begin{array}{l}\text { Sports boarding } \\
\text { school }\end{array}$} & Yes & 201 & 18 & - \\
\hline & No & 609 & 54 & - \\
\hline \multirow{3}{*}{$\begin{array}{l}\text { Leadership style of } \\
\text { coach }\end{array}$} & Autocratic & 204 & 19 & - \\
\hline & Democratic & 791 & 73 & - \\
\hline & Laissez-Faire & 82 & 8 & - \\
\hline \multirow{3}{*}{$\begin{array}{l}\text { Perception of direct } \\
\text { pressure applied from } \\
\text { sportsnet }\end{array}$} & & 1131 & - & $2.12(1.18)$ \\
\hline & No/Low & $447 / 281$ & $39 / 25$ & \\
\hline & $\begin{array}{l}\text { Medium/Elevated \& } \\
\text { High }\end{array}$ & $222 / 181$ & $20 / 16$ & \\
\hline \multirow{3}{*}{$\begin{array}{l}\text { Perception of indirect } \\
\text { pressure applied from } \\
\text { sportsnet }\end{array}$} & & 1135 & - & $1.57(0.95)$ \\
\hline & No/Low & $751 / 205$ & $66 / 18$ & \\
\hline & $\begin{array}{l}\text { Medium/Elevated \& } \\
\text { High }\end{array}$ & $110 / 69$ & $10 / 6$ & \\
\hline
\end{tabular}


595 Table 2

596 Willingness to compete hurt

\begin{tabular}{lllll}
\hline Score & Subcategory & N & \% & $\begin{array}{l}\text { M (SD) / } \\
\text { Mdn }\end{array}$ \\
\hline $\begin{array}{l}\text { Willingness to } \\
\text { compete hurt (4-20) }\end{array}$ & 1138 & - & 11.29 (3.71) \\
\hline
\end{tabular}

Items: I refuse to compete, if I...

$\begin{array}{ll} & 2.77(1.24) / \\ 1134- & 3.0\end{array}$

...do not feel physically resilient

Strongly disagree / Disagree / More or less agree / Agree / $9 / 23 / 20 / 31 / 17$ Strongly agree

$\begin{array}{ll} & 2.9(1.25) / \\ 1130- & 3.0\end{array}$

...have joint pain without moving

\begin{tabular}{|c|c|c|c|}
\hline \multirow[t]{2}{*}{$\begin{array}{l}\text { Strongly disagree / } \\
\text { Disagree / More or } \\
\text { less agree / Agree / } \\
\text { Strongly agree }\end{array}$} & & $12 / 24 / 20 / 30 / 14$ & - \\
\hline & 1127 & - & $\begin{array}{l}3.05(1.43) / \\
3.0\end{array}$ \\
\hline
\end{tabular}

...have to take Strongly disagree / Disagree / More or less agree / Agree / $23 / 18 / 17 / 25 / 17$ painkillers Strongly agree

$\begin{array}{ll} & 3.97(1.25) / \\ 1134- & 4.0\end{array}$

...have a fevery cold Strongly disagree / Disagree / More or less agree / Agree / 47/27/10/9/7 Strongly agree

597

598 
600

601

Table 3

Classification Tree Analyses of WCH: Gains Chart

\begin{tabular}{|c|c|c|c|c|}
\hline Knot & Description & $\mathbf{N}$ & Size (\%) & $\begin{array}{l}\text { WCH Mean } \\
\text { (SD) }\end{array}$ \\
\hline 8 & $\begin{array}{l}\text { Sportsgroup (Technical sports), autocratic } \\
\text { leadership style of coach }\end{array}$ & 38 & 3.4 & $\begin{array}{l}14.73 \\
(3.38)\end{array}$ \\
\hline 17 & $\begin{array}{l}\text { Sportsgroup (Aesthetic, Ball games, Weight } \\
\text { dependent), low direct social pressure to play } \\
\text { hurt, aged } 17 \text { \& } 18\end{array}$ & 45 & 4.0 & $\begin{array}{l}12.98 \\
(3.32)\end{array}$ \\
\hline 9 & $\begin{array}{l}\text { Sportsgroup (Technical sports), democratic or } \\
\text { laissez-faire leadership style of coach }\end{array}$ & 104 & 9.3 & $\begin{array}{l}12.75 \\
(3.76)\end{array}$ \\
\hline 7 & $\begin{array}{l}\text { Sportsgroup (Aesthetic, Ball games, Weight } \\
\text { dependent), medium-high direct social pressure } \\
\text { to play hurt }\end{array}$ & 228 & 20.4 & $\begin{array}{l}12,73 \\
(3.18)\end{array}$ \\
\hline 16 & $\begin{array}{l}\text { Sportsgroup (Aesthetic, Ball games, Weight } \\
\text { dependent), low direct social pressure to play } \\
\text { hurt, aged } 15 \& 16\end{array}$ & 44 & 3.9 & $\begin{array}{l}12.023 \\
(3.49)\end{array}$ \\
\hline 14 & $\begin{array}{l}\text { Sportsgroup (Aesthetic, Ball games, Weight } \\
\text { dependent), no direct social pressure to play } \\
\text { hurt, aged } 16-18\end{array}$ & 153 & 13.7 & $\begin{array}{l}11.53 \\
(3.68)\end{array}$ \\
\hline 12 & $\begin{array}{l}\text { Sportsgroup (Endurance, Power \& Missing), } \\
\text { medium-high direct social pressure to play hurt }\end{array}$ & 78 & 7.0 & $\begin{array}{l}11.33 \\
(3.24) \\
\end{array}$ \\
\hline 4 & $\begin{array}{l}\text { Sportsgroup (Endurance with focus on high } \\
\text { power, Antigravitation) }\end{array}$ & 118 & 10.5 & $\begin{array}{l}10.60 \\
(3.33)\end{array}$ \\
\hline 15 & $\begin{array}{l}\text { Sportsgroup (Aesthetic, Ball games, Weight } \\
\text { dependent), low direct social pressure to play } \\
\text { hurt, aged } 14\end{array}$ & 43 & 3.8 & $\begin{array}{l}10.47 \\
(2.81)\end{array}$ \\
\hline 11 & $\begin{array}{l}\text { Sportsgroup (Endurance, Power \& Missing), } \\
\text { low direct social pressure to play hurt }\end{array}$ & 80 & 7.1 & $\begin{array}{l}9.51 \\
(2.92)\end{array}$ \\
\hline 13 & $\begin{array}{l}\text { Sportsgroup (Aesthetic, Ball games, Weight } \\
\text { dependent), no direct social pressure to play } \\
\text { hurt, aged } 14 \text { \& } 15\end{array}$ & 52 & 4.6 & $\begin{array}{l}9.39 \\
(3.79)\end{array}$ \\
\hline 10 & $\begin{array}{l}\text { Sportsgroup (Endurance, Power \& Missing), no } \\
\text { direct social pressure to play hurt }\end{array}$ & 136 & 12.2 & $\begin{array}{l}8.35 \\
(3.09)\end{array}$ \\
\hline
\end{tabular}




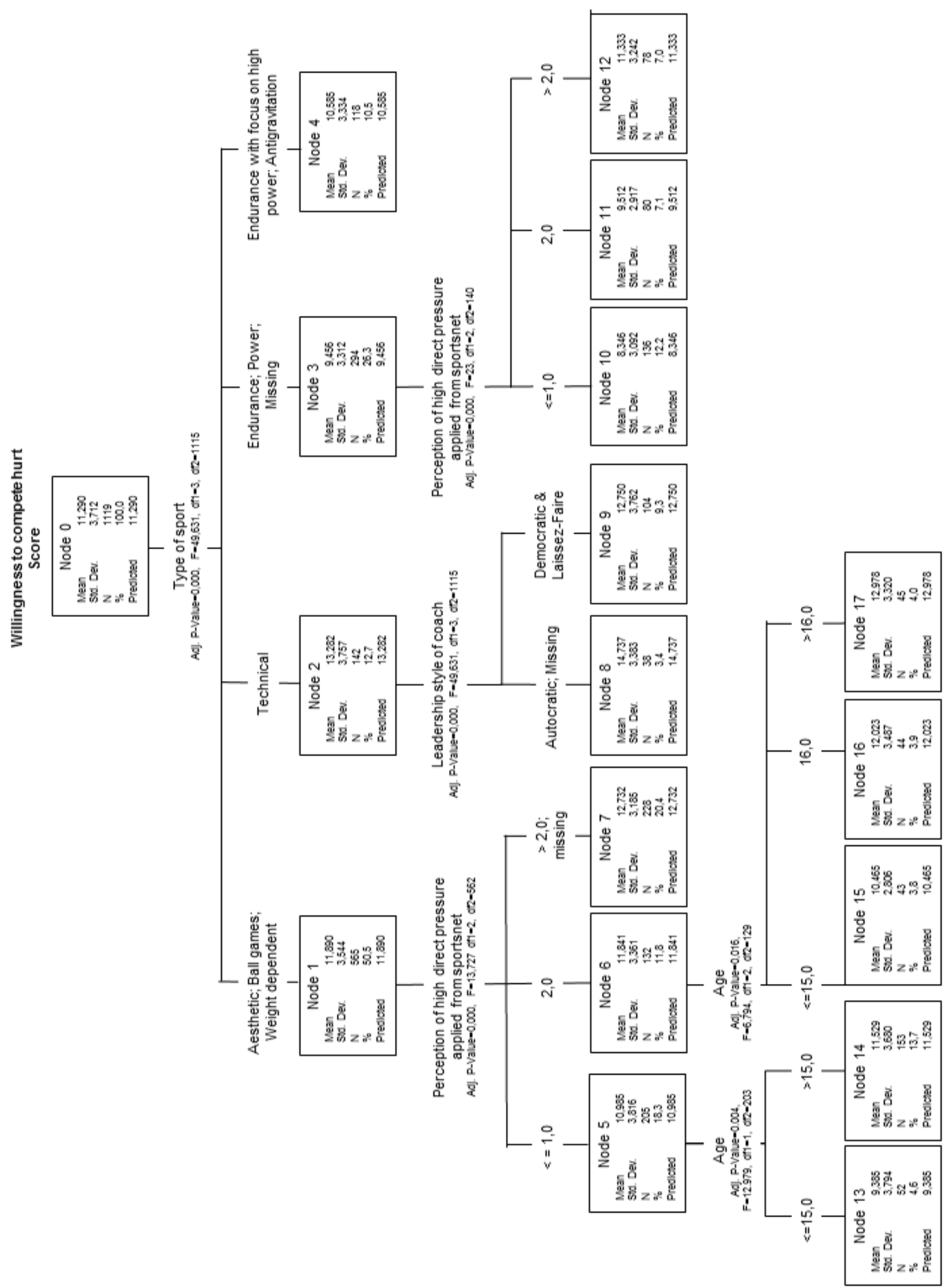

